\title{
Calculation of nonlinear elastic three-layer cylindrical shell of finite length with taking into account the continuous inhomogeneity caused by the temperature field
}

\author{
Vladimir I. Andreev ${ }^{1, *}$ and Lyudmila S. Polyakova ${ }^{1}$ \\ ${ }^{1}$ Moscow State University of Civil Engineering, 26 Yaroslavskoye Shosse, Moscow, 129337, Russia
}

\begin{abstract}
The article deals with the problem of determining the stressstrain state of a thick-walled cylindrical shell hinged on the rim near the ends, which is exposed to temperature effects. The shell consists of three layers: two layers of heat-resistant concrete and a steel outer layer. The calculation takes into account the continuous inhomogeneity of materials caused by a stationary temperature field, as well as the nonlinear nature of concrete deformation. The nonlinear problem with variable parameters of elasticity $E$ and $v$ was solved by the method of successive approximations.
\end{abstract}

\section{Introduction}

Technological equipment of chemical, petrochemical, and energy industries includes a number of structures subjected to systematic heating. Temperature effects and loads in such structures are axisymmetric, which allows significantly simplifying the solution of the problem to determine the stress-strain state. Reactors and regenerators of catalytic reforming and hydro treating units undergo periodic heating to a temperature of $500-600^{\circ} \mathrm{C}$ at a pressure up to $5 \mathrm{MPa}$ [2]. The reactor is usually a hollow cylinder with a diameter of up to $6 \mathrm{~m}$ and a height of up to $50 \mathrm{~m}$. The steel body of the device inside is lined with heatresistant concrete, which is covered with a shielding (corrosion-resistant) layer. Concrete linings are designed to reduce the temperature of the steel walls of the reactor to 200-230 ${ }^{\circ} \mathrm{C}$ at maximum process temperatures, ensure the resistance of the metal to hydrogen corrosion, reduce the metal consumption of the machines and reduce heat loss.

\section{Statement of the problem}

The problem of calculating a three-layer cylindrical shell on the influence of temperature is considered. Shell materials: internal corrosion-resistant layer of heat-resistant concrete on alumina cement (concrete №1) with a thickness of $50 \mathrm{~mm}$, the middle layer of heatresistant concrete on Portland cement (concrete №2) - $100 \mathrm{~mm}$, the outer layer of steel - 40 $\mathrm{mm}$. A constant temperature of $500^{\circ} \mathrm{C}$ is maintained inside.

\footnotetext{
*Corresponding author: asv@mgsu.ru
} 
To describe the nonlinear character of concrete deformation, experimentally obtained deformation diagrams of heat-resistant concrete are used [3].The solution uses a diagram $\sigma_{i}-\varepsilon_{i}$ that is described by a dependency with three constants [4]:

$$
\sigma_{i}=E \varepsilon_{i}-A \varepsilon_{i}^{\alpha} .
$$

The inhomogeneity of concrete [5] resulting from high temperatures is taken into account by replacing the constants $E, A$, and $\alpha$ with the functions $E(T), A(T)$ and $\alpha(T)$. To describe the deformation diagrams of heat-resistant concrete on Portland cement, the functions [6] were used:

$$
\left.\begin{array}{l}
E(T)=E_{01}+k_{E 1}\left(\frac{\Delta T}{T_{0}}\right)^{0.5}+m_{E 1}\left(\frac{\Delta T}{T_{0}}\right)^{2.5} ; \\
A(T)=A_{01}+k_{A 1}\left(\frac{\Delta T}{T_{0}}\right)^{0.8}+m_{A 1}\left(\frac{\Delta T}{T_{0}}\right)^{1.5} ; \\
\alpha(T)=\alpha_{01}+k_{\alpha 1}\left(\frac{\Delta T}{T_{0}}\right)^{1.2}+m_{\alpha 1}\left(\frac{\Delta T}{T_{0}}\right)^{1.5} ;
\end{array}\right\}
$$

To describe the deformation diagrams of heat-resistant concrete on alumina cement, the following functions were used:

$$
\left.\begin{array}{l}
E(T)=E_{02} \cdot \exp \left[k_{E 2}\left(\frac{\Delta T}{T_{0}}\right)^{0.9}+m_{E 2}\left(\frac{\Delta T}{T_{0}}\right)^{0.2}\right] ; \\
A(T)=A_{02} \cdot \exp \left[k_{A 2}\left(\frac{\Delta T}{T_{0}}\right)^{0.7}+m_{A 2}\left(\frac{\Delta T}{T_{0}}\right)^{0.3}\right] ; \\
\alpha(T)=\alpha_{02} \cdot \exp \left[k_{\alpha 2}\left(\frac{\Delta T}{T_{0}}\right)^{0.9}+m_{\alpha 2}\left(\frac{\Delta T}{T_{0}}\right)^{0.15}\right] .
\end{array}\right\}
$$

In formulae (2) and (3) $\Delta T=T-T_{0}$, where $T_{0}=20^{\circ} \mathrm{C}-$ normal temperature of concrete. The values of the coefficients are presented in table 1 .

Table 1. The values of coefficients in formulae (2), (3).

\begin{tabular}{|c|c|c|c|c|c|c|c|c|}
\hline $\begin{array}{c}E_{01}, \\
\mathrm{MPa}\end{array}$ & $k_{E 1}$ & $m_{E 1}$ & $A_{01}, \mathrm{MPa}$ & $k_{A 1}$ & $m_{A 1}$ & $\alpha_{01}$ & $k_{\alpha 1}$ & $m_{\alpha 1}$ \\
\hline $4.732 \cdot 10^{4}$ & -7142 & 3.5 & $1.7 \cdot 10^{6}$ & -169782 & 6285.14 & 1.62 & $2.0805 \cdot 10^{-2}$ & $-9.235 \cdot 10^{-3}$ \\
\hline$E_{02}, \mathrm{MPa}$ & $k_{E 2}$ & $m_{E 2}$ & $A_{02}, \mathrm{MPa}$ & $k_{A 2}$ & $m_{A 2}$ & $\alpha_{02}$ & $k_{\alpha 2}$ & $m_{\alpha 2}$ \\
\hline $5.472 \cdot 10^{4}$ & 0.14786 & -0.655 & $9.363 \cdot 10^{5}$ & $3.05 \cdot 10^{-3}$ & -2.15856 & 1.528 & $-1.8306 \cdot 10^{-3}$ & $-6.515 \cdot 10^{-2}$ \\
\hline
\end{tabular}

Figures 1 and 2 show the diagrams $\sigma_{i}-\varepsilon_{i}$. Figure 1 shows the deformation curves of concrete №1 at temperatures: $1-T=T_{0}=20^{\circ} \mathrm{C}, 2-T=100^{\circ} \mathrm{C}, 3-T=300^{\circ} \mathrm{C}, 4-T=$ $800^{\circ} \mathrm{C}$. Figure 2 shows the deformation curves of concrete №2 at temperatures: $1-T=$ $T_{0}=20^{\circ} \mathrm{C}, 2-T=300^{\circ} \mathrm{C}, 3-T=800^{\circ} \mathrm{C}$.

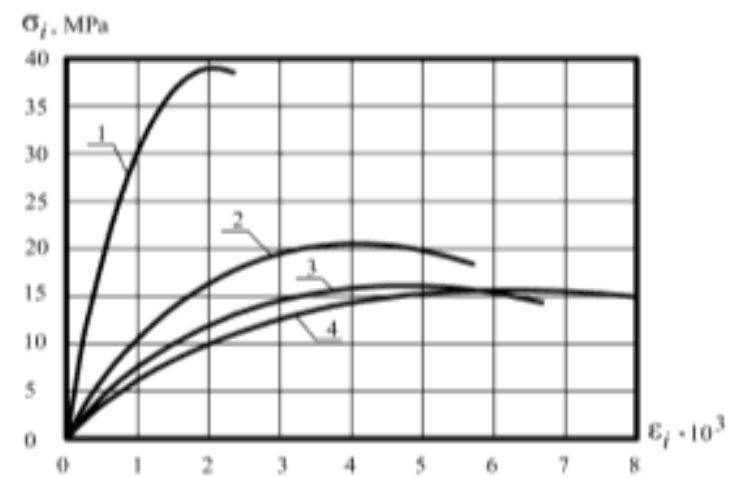

Fig. 1. Diagrams of the deformation of concrete №1 at different temperatures. 


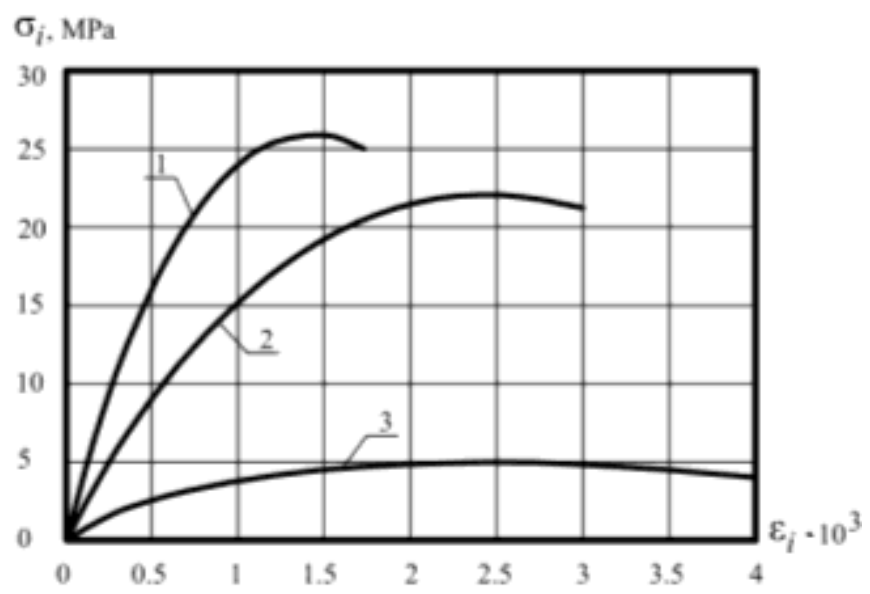

Fig. 2. Diagrams of the deformation of concrete №2 at different temperatures.

The values of the linear expansion temperature coefficient of concrete of different compositions depending on temperature are presented in[5]. The values $\alpha_{c}$ corresponding to the long-term heating mode under repeated exposure to temperature are taken in the problem. To approximate the data from [5], the following functions were used:

$$
\left.\begin{array}{c}
\alpha_{c 1}(T)=k_{1} \frac{\Delta T}{T_{0}}+k_{2}\left(\frac{\Delta T}{T_{0}}\right)^{1.5}+k_{3}\left(\frac{\Delta T}{T_{0}}\right)^{2} ; \\
(T)=\alpha_{T}+k_{4}\left(\frac{\Delta T}{T_{0}}\right)^{1.1}+k_{5}\left(\frac{\Delta T}{T_{0}}\right)^{1.2}+k_{6}\left(\frac{\Delta T}{T_{0}}\right)^{1.5},
\end{array}\right\}
$$

where $\alpha_{c 1}$ - linear expansion temperature coefficient of concrete № $1, \alpha_{c 2}$ - linear expansion temperature coefficient of concrete № 2. The values of the coefficients of the formulae (4) are presented in table 2.

Table 2. The values of coefficients in formulae (4).

\begin{tabular}{|c|c|c|c|c|c|c|}
\hline $\mathrm{k}_{1},{ }^{\circ} \mathrm{C}^{-1}$ & $\mathrm{k}_{2},{ }^{\circ} \mathrm{C}^{-1}$ & $\mathrm{k}_{3},{ }^{\circ} \mathrm{C}^{-1}$ & $\mathrm{k}_{4},{ }^{\circ} \mathrm{C}^{-1}$ & $\mathrm{k}_{5},{ }^{\circ} \mathrm{C}^{-1}$ & $\mathrm{k}_{6},{ }^{\circ} \mathrm{C}^{-1}$ & $\alpha_{\mathrm{T}},{ }^{\circ} \mathrm{C}^{-1}$ \\
\hline $1.328 \cdot 10^{-6}$ & $-3.4 \cdot 10^{-7}$ & $2.24 \cdot 10^{-8}$ & $2.14 \cdot 10^{-6}$ & $2.091 \cdot 10^{-6}$ & $1.92 \cdot 10^{-7}$ & $8.5 \cdot 10^{-6}$ \\
\hline
\end{tabular}

Figures (3) and (4) show functions approximating the values of the linear expansion temperature coefficient of concrete of two different compositions (the experimental values are shown by dots).

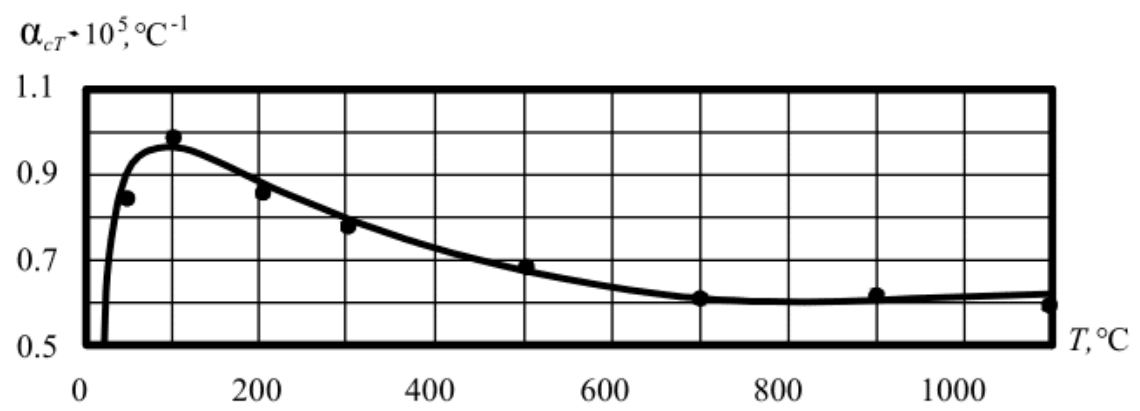

Fig. 3. Linear expansion temperature coefficient of concrete №1. 


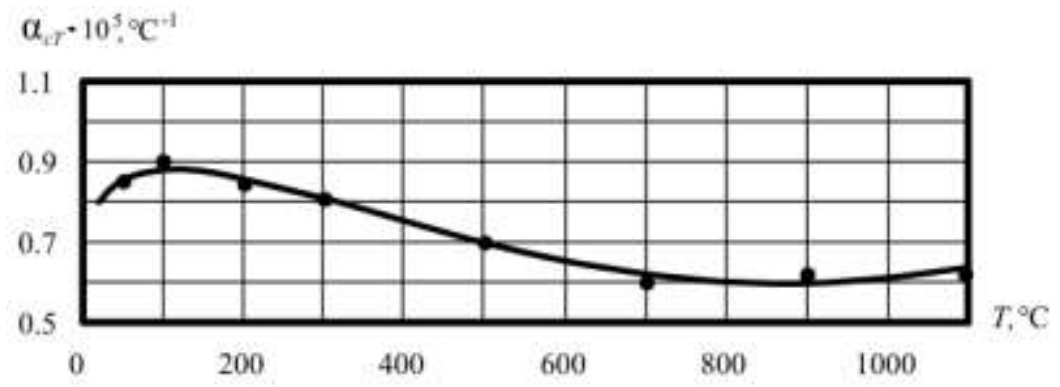

Fig.4. Linear expansion temperature coefficient of concrete №2.

The temperature distribution inside the multilayer wall is determined by the solution of the heat equation. The solution uses the following source data: $T_{i}=500^{\circ} \mathrm{C}-$ temperature inside the shell; $T_{0}=20^{\circ} \mathrm{C}-$ outside air temperature; $\alpha_{1}^{*}=162.8 \mathrm{~W} /\left(\mathrm{m}^{2 \circ} \mathrm{C}\right)-$ heat transfer coefficient from the internal environment to the concrete wall; $\lambda_{1}=0.8 \mathrm{~W} /\left(\mathrm{m}^{2 \circ} \mathrm{C}\right)-$ thermal conductivity coefficient of the first concrete layer; $\lambda_{2}=0.85 \mathrm{~W} / \mathrm{m}^{\circ} \mathrm{C}-$ thermal conductivity coefficient of the second concrete layer; $\lambda_{3}=25 \mathrm{~W} / \mathrm{m}^{\circ} \mathrm{C}$ - thermal conductivity coefficient of steel; $\alpha_{2}^{*}=7.6 \mathrm{~W} / \mathrm{m}^{2 \circ} \mathrm{C}$ - heat transfer coefficient from the outer surface of the shell to the air; $r_{1}=0.55 \mathrm{~m}, r_{2}=0.6 \mathrm{~m}, r_{3}=0.7 \mathrm{~m}, r_{4}=0.74 \mathrm{~m}$.

Figure 5 shows the temperature distribution in the three-layer wall: $T_{i}=500^{\circ} \mathrm{C}, T_{1}=$ $488.9^{\circ} \mathrm{C}, T_{2}=380.4^{\circ} \mathrm{C}, T_{3}=199.5^{\circ} \mathrm{C}, T_{4}=197.3^{\circ} \mathrm{C}, T_{o}=20^{\circ} \mathrm{C}$.
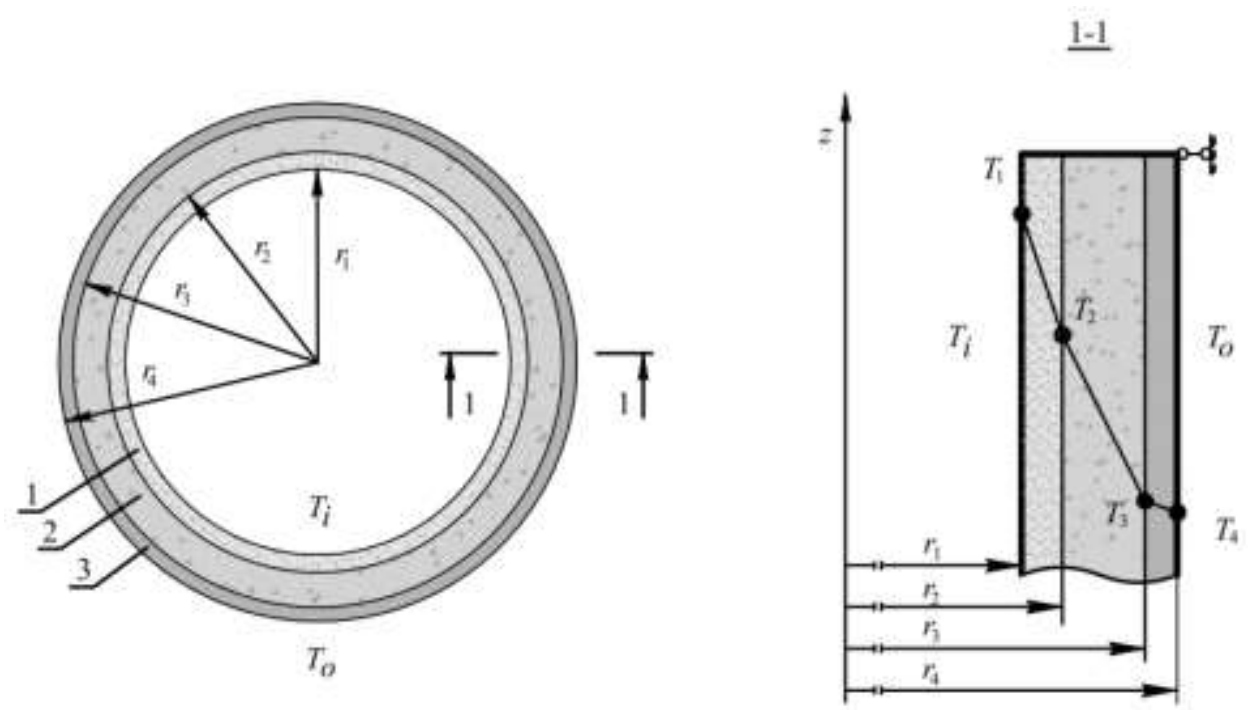

Fig. 5. Temperature distribution in a three-layer shell: 1 - concrete №1; 2 - concrete №2; 3 - steel.

The function of temperature variation along the radius for each layer has the form:

$$
T_{j}(r)=\ln (r / a) \frac{T_{j+1}-T_{j}}{\ln \left(r_{j+1} / r_{j}\right)}+\frac{T_{j} \ln \left(r_{j+1} / a\right)-T_{j+1} \ln \left(r_{j} / a\right)}{\ln \left(r_{j+1} / r_{j}\right)},
$$

where $j$ - layer number $(1,2, \ldots, n), a=1 \mathrm{~m}$.

Thus, the following temperature distribution functions for the first and second concrete layer are obtained: 


$$
\left.\begin{array}{l}
T_{1}(r)=-\left[1247 \ln \left(\frac{r}{a}\right)+256.4\right]^{\circ} \mathrm{C} ; \\
T_{2}(r)=-\left[1173 \ln \left(\frac{r}{a}\right)+218.9\right]^{\circ} \mathrm{C} .
\end{array}\right\}
$$

The temperature change in the thickness of the steel layer is not taken into account in the solution; the average value of the temperature is taken: $T_{3}=198.4^{\circ} \mathrm{C}$.

\section{Method of calculation}

Based on the method of successive approximations, a numerical method was developed for solving plane axisymmetric and central symmetric problems for thick-walled shells of physically nonlinear radially inhomogeneous material with arbitrary dependences of mechanical characteristics on the radius. Numerical solutions of test problems were obtained, comparison of the results of numerical and analytical solutions showed sufficient accuracy of the method developed [7].The solution under the condition of plane strain state (PSS) assumes that the cylinder is sufficiently long, and stresses arising at a distance from the ends are considered. This article proposes a solution to the problem taking into account local perturbations near the ends of the cylinder.

The solution obtained in the PSS conditions requires that normal forces $\sigma_{z}^{*}$ are distributed at the ends of the cylinder. In [8] it is proposed to determine the stresses in the cylindrical shell of finite length by summing the solution in the PSS condition and the solution for the cylindrical shell, at the ends of which compensating loads $\sigma_{z}$ are applied. The compensating loads are equal in magnitude and opposite in sign to the stresses $\sigma_{z}^{*}$ arising in the shell under PSS conditions, i.e. $\sigma_{z}=\left(-\sigma_{z}^{*}\right)$. A solution for a homogeneous linearly elastic material is considered in [8]. Using in the solution the functions $E(r)$ and $v(r)$ instead of the constants $E$ and $v$, we can obtain a solution for a radially inhomogeneous cylindrical shell. The linear problem is solved in the method of successive approximations at each stage of the iterative process. This allows summing the solution in the PSS condition and the solution for the cylindrical shell with compensating loads $\left(-\sigma_{z}^{*}\right)$ at each stage. The result is a solution for a radially inhomogeneous nonlinear elastic material.

To determine the stresses caused by compensating loads $\sigma_{z}=\left(-\sigma_{z}^{*}\right)$, we consider a longitudinal strip of unit width cut from a cylindrical shell. Such a strip can be considered as a beam on an elastic base, for which the deflection equation has the form:

$$
D \frac{d^{4} u}{d z^{4}}+K u=p(z)
$$

where $p(z)=0$ - intensity of the axisymmetric radial load;

$D=\frac{E h^{3}}{12\left(1-v^{2}\right)}-$ flexural stiffness of the cylindrical shell, replaces the flexural stiffness of the $\operatorname{rod} E I$;

$K=\frac{E h}{R^{2}}-$ shell stiffness in tension-compression in the circumferential direction, replaces the stiffness coefficient of the elastic base.

In the case of a radially inhomogeneous shell, equation (7) takes the form:

$$
\frac{d^{4} u}{d z^{4}} \frac{h^{2}}{12} \int_{r_{1}}^{r_{4}} \frac{E(r) d r}{1-v(r)^{2}}+u \int_{r_{1}}^{r_{4}} \frac{E(r) d r}{r^{2}}=0
$$

Where $h$ - shell thickness.

Dividing the integration interval into layers, we obtain: 


$$
\begin{gathered}
\frac{d^{4} u}{d z^{4}} \frac{h^{2}}{12}\left(\int_{r_{1}}^{r_{2}} \frac{E_{b 2}(r) d r}{1-v_{b 2}^{2}}+\int_{r_{2}}^{r_{3}} \frac{E_{b 1}(r) d r}{1-v_{b 1}^{2}}+\frac{E_{s}\left(r_{4}-r_{3}\right)}{1-v_{s}^{2}}\right)+ \\
+u\left(\int_{r_{1}}^{r_{2}} \frac{E_{b 2}(r) d r}{r^{2}}+\int_{r_{2}}^{r_{3}} \frac{E_{b 2}(r) d r}{r^{2}}+\frac{E_{s}\left(r_{4}-r_{3}\right)}{r_{s}^{2}}\right)=0 \\
D_{1} \frac{d^{4} u}{d z^{4}}+K_{1} u=0,
\end{gathered}
$$

or

where $E_{c 1}(r), v_{c 1}$-modulus of elasticity and Poisson's ratio of concrete №1;

$E_{c 2}(r), v_{c 2}$-modulus of elasticity and Poisson's ratio of concrete №2;

$E_{s}, v_{s}$ - modulus of elasticity and Poisson's ratio of steel.

For the convenience of integrating equation (9), we introduce the dimensionless variable: $\xi=\lambda z$, where $\lambda=\sqrt[4]{\frac{K_{1}}{4 D_{1}}}$. The parameter $\lambda$ depends on the flexural stiffness of the shell and the stiffness of the shell in tension-compression in the circumferential direction. Derivatives of the variables $\xi$ and $z$ are related by the ratio:

$$
\frac{d^{n}}{d z^{n}}=\lambda^{n} \cdot \frac{d^{n}}{d \xi^{n}}
$$

After replacing the variable, the differential equation (9) takes the form:

$$
\frac{d^{4} u(\xi)}{d \xi^{4}}+4 u(\xi)=0
$$

The solution of the homogeneous equation has the form:

$$
u(\xi)=\sin (\xi)\left[c_{1} \exp (\xi)+c_{3} \exp (-\xi)\right]+\cos (\xi)\left[c_{2} \exp (\xi)+c_{4} \exp (-\xi)\right] .
$$

Returning to the variable $z=\frac{1}{\xi} \sqrt[4]{\frac{K_{1}}{4 D_{1}}}$ and taking into account the hinged conditions of fastening from the two ends of the shell, we have: $u(z=0)=u(z=L)=0$. As a result, we obtain:

$$
c_{3}=\left[1-\exp \left(2 L \sqrt[4]{\frac{K}{4 D}}\right)\right] \cdot \operatorname{ctg}\left(L \sqrt[4]{\frac{K}{4 D}}\right) c_{2}-\exp \left(2 L \sqrt[4]{\frac{K}{4 D}}\right) c_{1}, c_{4}=-c_{2} .
$$

Compensating loads $\sigma_{z}=\left(-\sigma_{z}^{*}\right)$ are applied to the cylinder ends:

$$
\sigma_{z}(0)=\sigma_{z}(L)=-\sigma_{z}^{*} \text {. }
$$

Stresses $\sigma_{z}$ are determined through displacements:

$$
\sigma_{z}=-\frac{E}{1-v^{2}}\left(r-\frac{r_{1}+r_{4}}{2}\right) \frac{d^{2} u}{d z^{2}}
$$

From the condition $\sigma_{z}(L)=\sigma_{z}(0)$, we obtain $c_{2}$, expressed through $c_{1}$ :

$$
c_{2}=A c_{1} \text {, }
$$

where

$$
A=-\frac{\sin (L \lambda)[\cosh (L \lambda)+\sinh (L \lambda)+\cos (L \lambda)]}{2 \cos (L \lambda) \cosh (L \lambda)+\cos ^{2}(L \lambda)+1} .
$$

From the condition (14) we obtain:

$$
c_{1}=\int_{r_{1}}^{r_{4}} \sigma_{z}^{*}(r) d r\left[B \int_{r_{1}}^{r_{4}} \frac{E(r)}{\left(1-v(r)^{2}\right)}\left(r-\frac{r_{1}+r_{4}}{2}\right) d r\right]^{-1}
$$


where $B=2 \lambda^{2}\{1+\exp (2 L \lambda)-A \operatorname{ctg}(L \lambda)[1-\exp (2 L \lambda)]\}$.

Taking into account (12), (13), (16) and (17), we obtain the final expression for displacements. With a formula for the deflection curve, it is possible to calculate the corresponding bending stresses $\sigma_{z}^{b}$ and tangential stresses $\sigma_{\theta}^{b}$ for any $z$ value. The strain component in the tangential direction is equal for each layer: $\varepsilon_{\theta}^{b}=\frac{u}{r}$. The stress component in the tangential direction is determined from Hooke's law:

$$
\sigma_{\theta}^{b}=E \varepsilon_{\theta}^{b}+v \sigma_{z}^{b}=E \frac{u}{r}+v \frac{E}{1-v^{2}}\left(\frac{r_{1}+r_{4}}{2}-r\right) \frac{d^{2} u}{d z^{2}} .
$$

The resulting stresses in the cylinder of finite length are obtained by summing the stresses calculated for the infinite cylinder $-\sigma_{z}^{*}, \sigma_{\theta}^{*}, \sigma_{r}^{*}$, and the stresses arising from the action of the compensating loads $\left(-\sigma_{z}^{*}\right)$ applied at the ends of the cylinder $-\sigma_{z}^{b}, \sigma_{\theta}^{b}$.

\section{Results}

The results of the calculation of the three-layer shell of length $L=10$ mare presented in the figures:
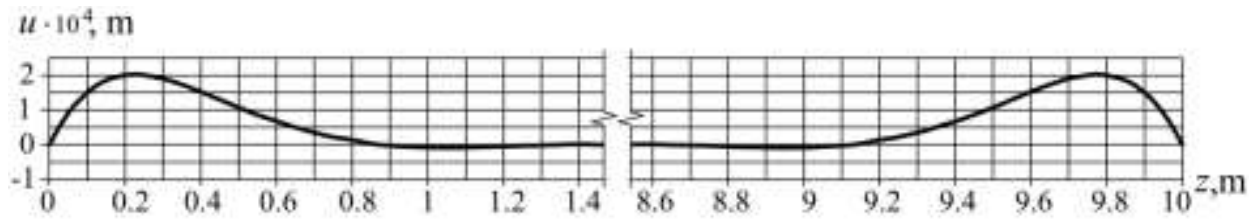

Fig. 6. The curve of the deflection from the action of stresses $\left(-\sigma_{z}^{*}\right)$.
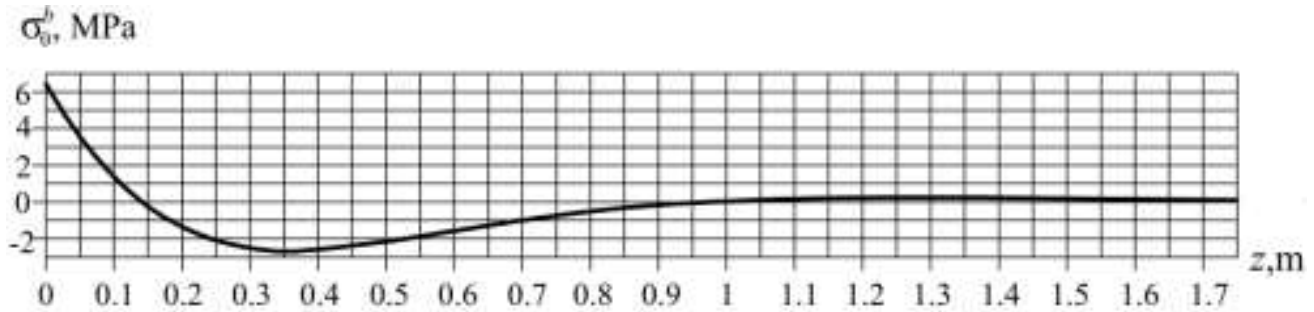

Fig. 7. Stresses $\sigma_{\theta}^{b}$ on the inner surface of the shell $\left(r=r_{1}\right)$.

Figure 7 demonstrates that the positive maximum of the function is reached at $z=0$ and $z=L=10 \mathrm{~m}$, the negative maximum of the function is reached at approximately $z=$ $0,35 \mathrm{~m}$. It can be seen from the graphs that the stresses arising near the fixed ends of the cylinder decrease rapidly with increasing of distance from the end of the shell.

Figures 8 and 9 show the stresses $\sigma_{\theta}^{b}, \sigma_{\theta}^{*}$ and resulting stresses $\sigma_{\theta}$ at $z=0$ and $z=$ $0,35 \mathrm{~m}$ respectively. Due to the difference in material properties $\left(E_{c 1}<E_{c 2}<E_{s}\right)$ of different layers, there is a redistribution of stresses in favor of the steel layer and, to a lesser extent, in favor of the middle concrete layer. 


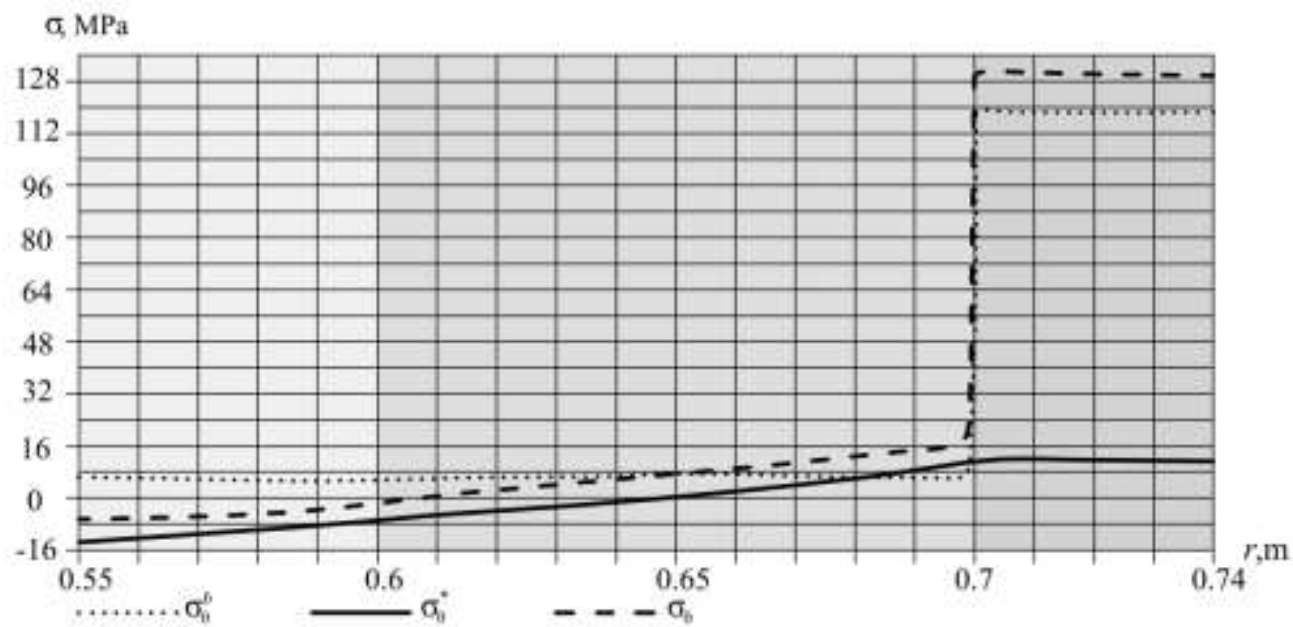

Fig. 8. Stresses $\sigma_{\theta}^{b}, \sigma_{\theta}^{*}$ and resulting stresses $\sigma_{\theta}$ at $z=0$.

The most dangerous is the stretched zone of the second concrete layer near $r=0,7 \mathrm{~m}$, where the stresses increase by about $30 \%$ compared to the sections distant from the ends of the cylinder.

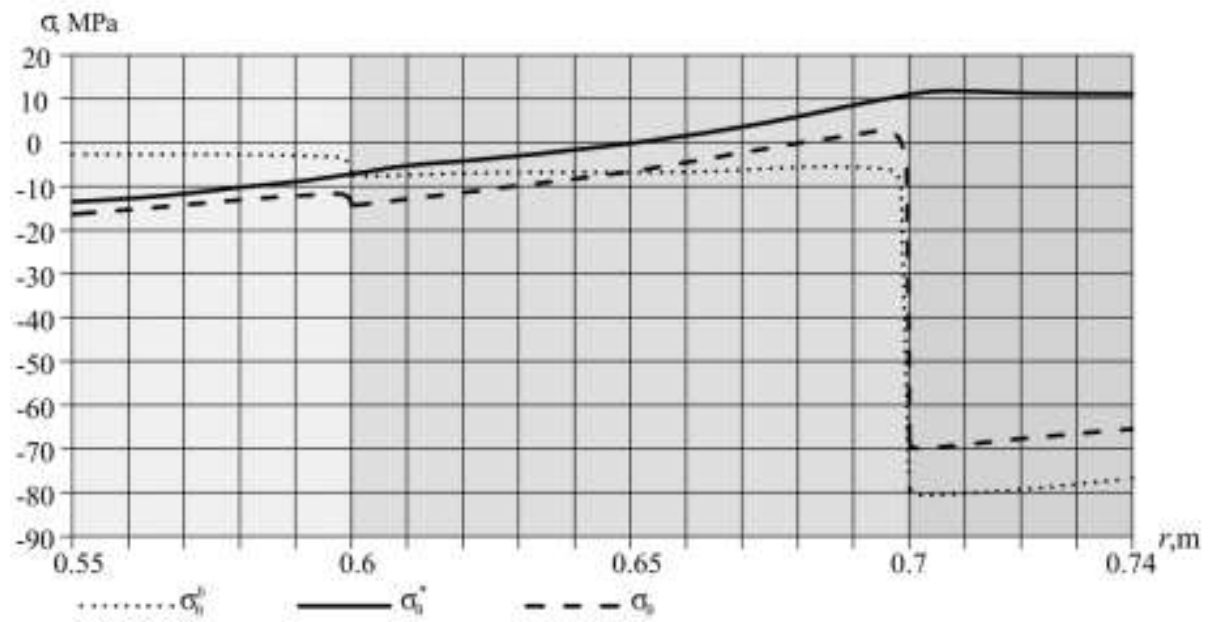

Fig. 9. Stresses $\sigma_{\theta}^{*}, \sigma_{\theta}^{b}$ and resulting stresses $\sigma_{\theta}$ at $z=0,35 \mathrm{~m}$.

The most dangerous is the compressed zone of both concrete layers, the stresses in the first layer increase by about 23\%,and in the second (middle) layer by almost 2 times compared with the sections distant from the ends of the cylinder.

Figure 10 demonstrates the resulting stresses $\sigma_{\theta}$ in the interval $z \in[0 ; 1,5]$. 


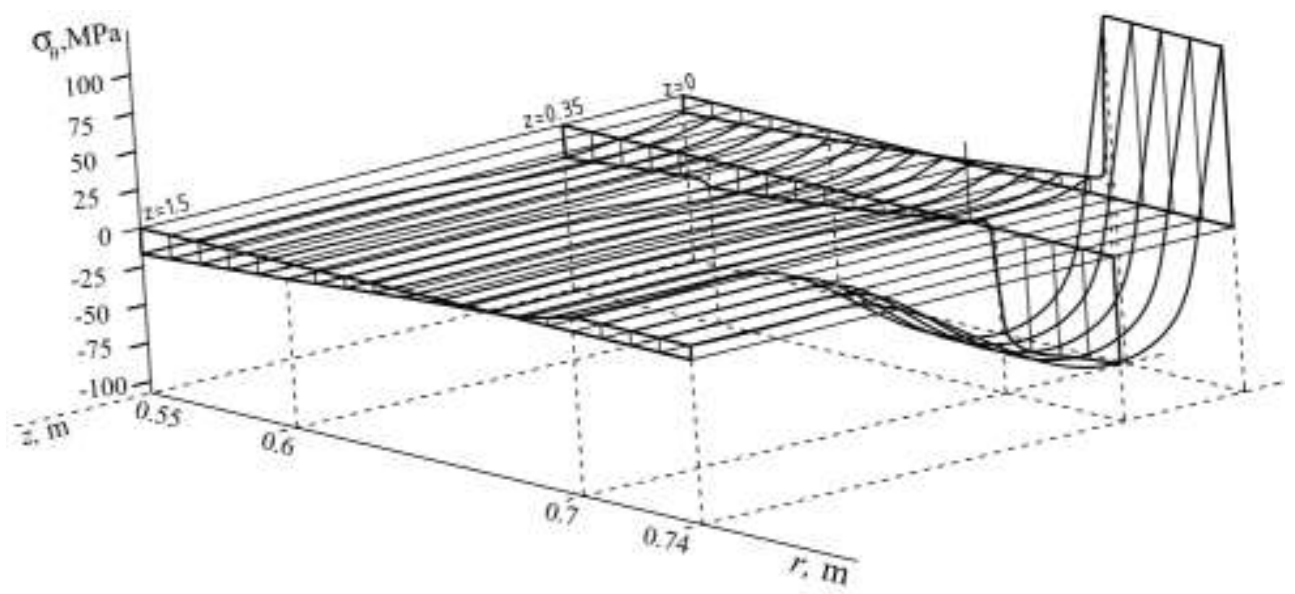

Fig. 10. Resulting stresses $\sigma_{\theta}$ on the interval $z \in[0 \div 1.5] \mathrm{m}$.

\section{Conclusion}

The increase in stress near the ends of the cylinder due to the fact that it depends on the deflection $u$ is local and decreases rapidly with increasing distance from the end $z$.For the shell considered in this article, the most dangerous are the sections at distances $z=0$ and $z=0.35$. There is a significant increase in stresses in the steel layer. In concrete layers the maximum stresses increase by $30 \%$ in the stretched zone at $z=0$ and by $23 \%$ in the compressed zone at $z=0.35$.

Numerous studies of the authors [9 - 13 et al.] demonstrate that the inhomogeneity of various materials (concrete, soils, polymers, etc.) due to high temperature leads to a decrease in stresses in structures compared to homogeneous bodies. The opposite effect is observed in the case of negative temperatures [14].

Taking into account the nonlinear work of materials increases the effect of inhomogeneity on the stress-strain state of bodies [6, 7]. Hence, it can be concluded that it is important to take into account both factors - inhomogeneity and nonlinear behavior of materials.

\section{Acknowledgment}

This work was financially supported by the Ministry of Russian Education \# 7.6163.2017/6.7

\section{References}

1. V. I. Andreev, Mechanics of inhomogeneous bodies (Yurayt, Moscow, 2015)

2. G. I. Zavelev, Non-metallic linings for equipment of oil and petrochemical industries (Publ. House Gostoptekh, Moscow, 1960)

3. A.V. Ushakov, The basic laws of deformation of conventional and heat-resistant concrete, Dis. kand. technical Sciences (Volgograd, 2006)

4. P. A. Lucash, The foundations of nonlinear structural mechanics (Publ. House Stroyizdat, Moscow, 1978) 
5. Russian Standard SP 27.13330.2011

6. L.S. Polyakova, V.I. Andreev, AER 143, 86 (2017)

7. V.I. Andreev, L.S. Polyakova, IJCCSE 12, 36 (2016)

8. S.P. Timoshenko, J. Goodier, Theory of elasticity (Nauka, Moscow, 1975)

9. V.I. Andreev, D.A. Kapliy, Advanced Materials Research 1006-1007, 177 (2014)

10. V.I.Andreev, A.N. Leontiev, MATEC Web of Conferences 129, 05006 (2017)

11. A.S. Chepurnenko, V.I. Andreev, B.M. Yazyev, A.N. Beskopylny, MATEC Web of Conferences 67, 06059 (2016)

12. V.I. Andreev, A.S. Avershyev, Proceedia Engineering 111, 30 (2015)

13. V.I. Andreev, E3S Web of Conferences 33, 02027 (2018)

14. V.I. Andreev, T.K. Kayupov, MATEC Web of Conferences 110, 08053 (2017) 